\title{
Incidence of cardiac sarcoidosis in those with extra-cardiac disease without known cardiac involvement - a CMR study
}

Theodore M Murphy*, Deirdre F Waterhouse, Stephanie I James, Cliona Kenny, Rory O'Hanlon

From 19th Annual SCMR Scientific Sessions

Los Angeles, CA, USA. 27-30 January 2016

\section{Background}

Cardiac death is the leading cause of mortality in patients with sarcoidosis. However, the incidence of cardiac sarcoidosis in those with extracardiac disease has yet to be formally examined. Cardiovascular magnetic resonance (CMR) imaging with late gadolinium enhancement (LGE) may identify the myocardial infiltration of cardiac sarcoidosis (CS), and thus allow risk stratification of these at risk individuals. We therefore investigated the incidence of CS in patients with extracardiac sarcoidosis without cardiac manifestations using CMR-LGE.

\section{Methods}

Seventy-two patients with clinically and radiologically diagnosed pulmonary sarcoidosis, without signs or symptoms of cardiovascular involvement, were enrolled over a three-year period. LGE-CMR was performed on all patients. The presence of LGE in the left ventricular myocardium was considered diagnostic for CS. Patients were classified as CS or non-CS based on the CMR-LGE findings.

\section{Results}

Mean age was $51 \pm 19$ years, with a female predominance (61\%). CS was detected in nineteen patients (23\%). When compared to those patients without LGE, patients with CS had higher rates of previously documented non-sustained ventricular tachycardia ( $22 \%$ vs. $5 \%$ ), a greater prevalence of an abnormal ECG (52\% vs. $18 \%$ ) and a higher heart rate during CMR (82bpm vs. 72bpm).

\section{Conclusions}

CMR should be considered as an adjunct to conventional diagnostic workup in all patients with pulmonary sarcoidosis. Long-term follow-up of consecutive patients with isolated CS is needed to determine the natural history and to accurately define rates of ventricular arrhythmias.

Published: 27 January 2016

doi:10.1186/1532-429X-18-S1-P251

Cite this article as: Murphy et al:: Incidence of cardiac sarcoidosis in those with extra-cardiac disease without known cardiac involvement - a CMR study. Journal of Cardiovascular Magnetic Resonance 2016 18(Suppl 1):P252.
Submit your next manuscript to BioMed Central and take full advantage of:

- Convenient online submission

- Thorough peer review

- No space constraints or color figure charges

- Immediate publication on acceptance

- Inclusion in PubMed, CAS, Scopus and Google Scholar

- Research which is freely available for redistribution 